\title{
Interação Genótipo x Ambiente em Características de Crescimento de Bovinos da Raça Nelore no Mato Grosso do Sul
}

\author{
Fábio Luiz Buranelo Toral ${ }^{1}$, Luiz Otávio Campos da Silva ${ }^{2}$, Elias Nunes Martins ${ }^{3}$, Andrea \\ Gondo $^{4}$, Sandra Maria Simonelli ${ }^{5}$
}

\begin{abstract}
RESUMO - O efeito da interação genótipo $\mathrm{x}$ ambiente sobre a classificação de touros, com base nos seus valores genéticos preditos (VGs), foi estudado para os pesos ao nascimento (PN), à desmama (P205), aos 12 (P365) e aos 18 (P550) meses de idade de bovinos Nelore criados nas microrregiões de Alto Taquari, Campo Grande e Pantanal, MS. Os dados foram analisados por microrregião e para todas as regiões em conjunto. Os componentes de (co)variância e parâmetros genéticos foram estimados pelo método da máxima verossimilhança restrita, utilizando um modelo animal que incluiu o efeito aleatório aditivo direto e os efeitos fixos de sexo e de grupo de contemporâneos (fazenda, ano, época e região de nascimento). Os resultados comprovaram que os componentes de (co)variância aditivos diretos e residuais foram diferentes entre as regiões. As estimativas de herdabilidade para as características variaram de 0,16 a 0,66 (PN); 0,36 a 0,59 (P205); 0,35 a 0,49 (P365) e 0,30 a 0,45 (P550). As correlações de Pearson entre os VGs dos touros, obtidos para cada par de microrregiões e para cada microrregião e todas as microrregiões em conjunto, apresentaram médias iguais a 0,11 e 0,80 (PN); 0,38 e 0,88 (P205); 0,38 e 0,88 (P365) e 0,39 e 0,87 (P550), respectivamente. Apesar dos altos valores das correlações para as análises das microrregiões em conjunto com as análises por microrregião, os resultados indicam que existem evidências de interação genótipo x ambiente e que a avaliação genética regional, quando disponível, pode ser mais adequada que a avaliação estadual.
\end{abstract}

Palavras-chave: avaliação genética, classificação, correlação, herdabilidade, modelo animal

\section{Genotype $x$ Environment Interaction in Growth Traits of Nellore Cattle of Mato Grosso do Sul}

\begin{abstract}
The effect of genotype x environment interaction on body weight at birth (BW), weaning (W205), 12 (W365) and 18 (W550) months of age of Nellore cattle raised in the regions of Alto Taquari, Campo Grande and Pantanal, MS, Brazil, was studied. The data were analyzed for each region separately and for all regions together. Variance and covariance components and genetic parameters were estimated by the restricted maximum likelihood method, using an animal model that included the random additive direct effect, and the fixed effects of sex and contemporary group (herd, year, season and region of birth), and sires were ranked based on their breeding values (BV). The results showed that the additive direct and residual variances were different among regions. The heritability estimates ranged from 0.16 to 0.66 (BW), 0.36 to 0.59 (W205), 0.35 to 0.49 (W365) and 0.30 to 0.45 (W550), depending on the region. Pearson's correlation coefficients between BVs of sires, obtained for each pair of regions, showed means equal to 0.11 (BW), 0.38 (W205), 0.38 (W365) and 0.39 (W550). When the correlations were for the BVs obtained for each region with the $\mathrm{BVs}$ obtained for all regions together, the estimates were higher showing means equal to 0.80 (BW), 0.88 (W205), 0.88 (W365) and 0.87 (W550). Despite the high values of these last ones, the results show evidence of genotype $\mathrm{x}$ environment interaction, and that regional genetic evaluations, when available, can be more useful than a state evaluation.
\end{abstract}

Key Words: animal model, correlation, genetic evaluation, heritability, rank

\section{Introdução}

O Brasil não apresenta um sistema padrão de exploração de gado bovino em todo o seu território e a diversidade de sistemas de exploração está, em grande parte, ligada a diferenças de fatores climáticos, econômicos e históricos e à disponibilidade de recursos naturais que influenciam a produção animal. Por outro lado, mesmo os sistemas de produção variando com a conjuntura econômica do país, alguns desses fatores são relativamente persistentes, especialmente os ligados aos recursos naturais, como clima,

\footnotetext{
${ }_{1}^{1}$ Aluno do curso de Doutorado em Zootecnia da Universidade Federal de Viçosa. Bolsista do CNPq. E.mail: flbtoral@hotmail.com

2 Pesquisador da Embrapa Gado de Corte, Campo Grande, MS. E.mail: locs@cnpgc.embrapa.br

3 Professor do Departamento de Zootecnia da UEM, Maringá, PR. E.mail: enmartins@uem.br

${ }^{4}$ Analista de Sistemas da Embrapa Gado de Corte. E.mail: andrea@cnpgc.embrapa.br

${ }^{5}$ Aluna do Programa de Pós-Graduação em Zootecnia (Produção Animal) da UEM.
} 
topografia, vegetação e solo (Arruda \& Sugai, 1994), que, por influenciarem a qualidade e a disponibilidade de forragem, atuando diretamente sobre a eficiência dos sistemas de produção de carne bovina, criam as chamadas áreas homogêneas de produção.

Uma importante consideração a ser feita sobre a produção econômica dos animais domésticos refere-se à escolha do ambiente onde se deve praticar a seleção dos animais de reprodução, tendo em vista o local em que deverão viver e procriar. As progênies de um mesmo reprodutor podem não repetir o desempenho dos pais, caso sejam criadas em microrregiões ou fazendas diferentes, evidenciando a necessidade de cuidados na compra de reprodutores e, ou, sêmen, em razão da existência de interação genótipo x ambiente (Nobre et al., 1987).

A interação genótipo $\mathrm{x}$ ambiente existe quando o mérito relativo de dois ou mais genótipos é dependente do ambiente no qual são comparados (Mascioli, 2000) e, ou, quando um genótipo é melhor em um ambiente e não o é em outro (Falconer \& Mackay, 1996).

O mérito genético de um animal, seja ele avaliado pelo próprio desempenho seja pelo desempenho de sua progênie, pode ser influenciado de forma significativa por mudanças no ambiente de criação, como constatado por Mascioli (2000), que afirmou ser a seleção de touros superiores, se realizada com base em prova de ganho de peso em confinamento, um critério ineficiente na identificação de animais superiores para a produção de filhos criados a pasto.

Esta interação é mais importante na fase pósdesmama que na pré-desmama (Cardellino et al., 1997), pois existe forte relação de dependência criamãe nos mamíferos, de modo que, se a cria está sob proteção da mãe (efeito materno), espera-se que não sofra completamente os efeitos da diferença entre ambientes. Por outro lado, menores valores dos componentes de variância e parâmetros genéticos maternos do peso aos 420 dias de idade indicam a redução desse efeito à medida que o animal se torna adulto (Campêlo et al., 2001).

Neste trabalho, objetivou-se estudar o efeito da interação genótipo $\mathrm{x}$ ambiente sobre características de crescimento de bovinos da raça Nelore criados em três microrregiões homogêneas do Estado do Mato Grosso do Sul.

\section{Material e Métodos}

Foram estudadas as informações de 20.178 bovinos da raça Nelore, filhos de 788 touros e 12.428 vacas com idade entre 2,5 e 15 anos, concebidos via inseminação artificial, nascidos no período de 1976 a 1999 e criados exclusivamente em pastagens de 77 fazendas das microrregiões homogêneas de Alto Taquari, Campo Grande e Pantanal, classificadas como MRH339, MRH342 e MRH338, respectivamente, pelo IBGE (IBGE, 1970). Os dados são pertencentes ao Programa de Controle do Desenvolvimento Ponderal da Associação Brasileira de Criadores de Zebu. Na Tabela 1, encontram-se os números de animais, de touros, de animais na matriz de parentesco, de fazendas e de grupos de contemporâneos das microrregiões homogêneas estudadas.

A seguir, é apresentada a descrição de cada região estudada, segundo Arruda \& Sugai (1994). A microrregião de Alto Taquari, localizada nas terras altas do planalto mato-grossense, abrange parte das bacias dos rios Paraná e Paraguai, cuja topografia dominante é a de chapadões. O clima é do tipo subquente úmido, com três meses secos (junho a agosto). A pluviometria anual, em torno de $1.250 \mathrm{~mm}$, intensifica-se nos meses de dezembro, janeiro e fevereiro. O solo predominante é do tipo areias quartzosas distróficas, de baixa fertilidade. Grande parte desta microrregião tem como vegetação natural o cerrado.

Tabela 1 - Números de animais (NA), de touros (NT), de animais na matriz de parentesco (NAMP), de fazendas (NF) e de grupos de contemporâneos (NGC) das microrregiões homogêneas estudadas

Table 1 - Number of animals (NA), number of bulls (NB), number of animals in the relationship matrix (NARM), number of farms (NF) and number of contemporary groups (NCG) by studied regions

\begin{tabular}{lccccc}
\hline Microrregião & NA & NT & NAMP & NF & NGC \\
Region & & $N B$ & NARM & & NCG \\
\hline Alto Taquari & 3.554 & 174 & 5.348 & 15 & 121 \\
Campo Grande $^{\text {Pantanal }}$ & 7.202 & 445 & 11.856 & 39 & 355 \\
Arquivo completo $^{1}$ & 9.422 & 364 & 15.022 & 23 & 307 \\
Full data set $^{1}$ & 20.178 & 788 & 31.736 & 77 & 783 \\
\hline
\end{tabular}

${ }^{1}$ Arquivo com os dados das três microrregiões.

${ }_{1}^{1}$ Data set with records from the three regions. 
A topografia predominante na microrregião de Campo Grande é plana a levemente ondulada. O clima é subquente úmido com dois a três meses secos (junho a agosto) e precipitação anual variando de 1.250 a $1.500 \mathrm{~mm}$, com maior concentração nos meses de novembro, dezembro e janeiro. Predominam os solos do tipo latossolo vermelho-escuro e roxo, de média e boa fertilidade. Basicamente três tipos de vegetação natural ocorrem na região: o cerrado, o campo limpo e a mata do tipo floresta subcalcifólia, características naturais bastante propícias ao desenvolvimento de sistemas de produção eficientes.

$\mathrm{Na}$ microrregião do Pantanal, predominam cordilheiras com cobertura vegetal de cerrado ou mata, aplainadas com arbustos e gramíneas, vazantes e lagoas regionalmente denominadas baías. A precipitação anual média é de $1.200 \mathrm{~mm}$ e os solos geralmente são arenosos, com baixa fertilidade, resultando em baixo rendimento das pastagens naturais.

As características estudadas foram peso ao nascimento $(\mathrm{PN})$, peso à desmama padronizado para 205 dias (P205), peso aos 12 meses de idade padronizado para 365 dias (P365) e peso aos 18 meses de idade padronizado para 550 dias (P550). Inicialmente, os dados foram submetidos a análise de variância, para obtenção das médias e comparação das médias entre regiões e entre sexos (SAS, 2001).

Para cada microrregião, formaram-se dois arquivos, um de dados e um completo com os dados das três microrregiões.

Para garantir a conexidade entre os grupos de contemporâneos, utilizaram-se os critérios sugeridos por Fries \& Roso (1997), que sugerem que, para ser considerado conectado, um grupo de contemporâneos precisa ter pelo menos 10 laços genéticos diretos (um laço genético direto entre dois grupos de contemporâneos é estabelecido quando existe um touro ou uma vaca com uma progênie em cada um destes grupos) e pelo menos três pais diferentes.

Os componentes de (co)variância e parâmetros genéticos foram estimados utilizando-se o método da máxima verossimilhança restrita (REML), enquanto os valores genéticos preditos foram obtidos pelo método do melhor preditor linear não-viesado (BLUP), por intermédio do programa MTDFREML (Boldman et al., 1995). Foi utilizado um modelo animal, com os efeitos genético aditivo direto e residual (efeito aleatório) e, como fixos, os efeitos do sexo e do grupo de contemporâneos, que agrupou as informações de fazenda, ano, época e região de nascimento. As épocas de nascimento estabelecidas foram: época 1 - nascimentos nos meses de outubro, novembro e dezembro; época 2 - nascimentos nos meses de janeiro, fevereiro e março; época 3 - nascimentos nos meses de abril, maio e junho; e época 4 nascimentos nos meses de julho, agosto e setembro. A idade da vaca no dia do parto foi utilizada como covariável linear e quadrática para as características $\mathrm{PN}$ e P205.

Em análise preliminar, verificaram-se elevadas correlações (superiores a 0,90 ) entre os valores genéticos preditos para $\mathrm{P} 205$, quando foram realizadas as análises bicaracter PN com P205, P205 com P365 e P205 com P550. Assim, o P205 foi utilizado como característica de ligação entre as demais. Entretanto, consideraram-se os componentes de (co)variância e parâmetros genéticos para P205 como os encontrados quando este foi analisado juntamente com PN, por este não necessitar de padronização, o que diminui o erro existente na estimação dos componentes de (co)variância.

Foram calculadas as correlações de Pearson, entre os valores genéticos preditos, e de Spearman entre a classificação (com base nos valores genéticos), dos touros com filhos em pelo menos duas microrregiões, por meio do PROC CORR (SAS, 2001) e a hipótese de nulidade (ausência de correlação) foi testada a $5 \%$ de probabilidade.

\section{Resultados e Discussão}

Na Tabela 2, são apresentadas as médias de quadrados mínimos, ajustadas para ano e época de nascimento, dos pesos ao nascimento $(\mathrm{PN})$, à desmama (P205), aos 12 (P365) e aos 18 (P550) meses de idade de bovinos da raça Nelore nas microrregiões homogêneas estudadas e as médias gerais para machos e fêmeas, ajustadas para ano, época e região de nascimento.

Houve efeito $(\mathrm{P}<0,05)$ do sexo do animal sobre as características estudadas, independentemente das microrregiões consideradas, sendo que os PN, P205, P365 e P550 das fêmeas, foram, em média, 5, 8, 11 e $13 \%$ inferiores aos dos machos, resultado semelhante ao relatado por Machado et al. (1997), que constataram, em animais da raça Nelore, superioridade de 4,$7 ; 7,2 ; 9,8$ e $11,8 \%$ nos pesos dos machos em relação às fêmeas, o que pode ser explicado por Sakaguti et al. (2001), que, ao constatarem

R. Bras. Zootec., v.33, n.6, p.1445-1455, 2004 
comportamento similar em bovinos da raça Tabapuã, informaram que o aumento das diferenças entre pesos corporais de machos e fêmeas evidencia a diferença da taxa de crescimento dos dois sexos, fato provavelmente relacionado às diferenças fisiológicas e hormonais, que se intensificam à medida que o animal atinge a puberdade e inicia sua vida sexual.

Os animais da microrregião de Alto Taquari foram 1,$9 ; 2,7 ; 6,0$ e $9,3 \%$ (machos) e 2,$1 ; 3,5 ; 6,8$ e $7,9 \%$ (fêmeas) mais leves $(\mathrm{P}<0,05)$ ao nascimento, à desmama, aos 12 e aos 18 meses de idade, respectivamente, em relação aos da microrregião de Campo Grande e foram, na mesma ordem, 2,9; 4,3; 8,$9 ; 8,3 \%$ (machos) e 3,1; 5,0; 8,3 e 7,5\% (fêmeas) mais leves que os da microrregião do Pantanal. Os animais da microrregião de Campo Grande foram 1,$0 ; 1,7$ e 2,9\% (machos) e 1,0; 1,5 e 1,6\% (fêmeas) mais leves $(\mathrm{P}<0,05)$ ao nascimento, à desmama e aos 12 meses de idade, respectivamente, em relação aos animais da microrregião do Pantanal.

$\mathrm{O}$ efeito das microrregiões sobre os pesos estudados evidencia as particularidades de cada microrregião. De acordo com Arruda \& Sugai (1994), a microrregião de Campo Grande apresenta o solo com maior fertilidade, maior proporção de pastagens cultivadas $(67,4 \%)$ e maior taxa de lotação $(0,64$ bovino adulto/ha) em relação às microrregiões de Alto Taquari e Pantanal, onde existem aproximadamente 43 e $14,8 \%$ de pastagens cultivadas e 0,33 e 0,35 bovino adulto/ha, respectivamente.

Apesar de ter melhores condições para crescimento, os animais da microrregião de Campo Grande não foram mais pesados que os animais criados na microrregião do Pantanal, provavelmente pela maior lotação predominante naquela microrregião, que sugere maior produção por área, em detrimento ao ganho de peso por animal. Todavia, a diferença entre o peso dos animais da microrregião de Alto Taquari e do Pantanal pode ser, parcialmente, justificada pela utilização de genótipos e, ou, sistemas de produção mais adequados.

As herdabilidades $\left(h^{2}\right)$ e as variâncias genéticas aditivas $\left(\sigma_{a}^{2}\right)$ e ambientais $\left(\sigma_{e}^{2}\right)$ de PN, P205, P365 e $\mathrm{P} 550$, para os arquivos de cada microrregião, e para o arquivo completo, encontram-se na Tabela 3.

As estimativas de herdabilidade para a microrregião de Alto Taquari, que apresenta condições de ambiente menos favoráveis à produção animal, foram superiores às demais. A variação constatada na herdabilidade concorda com resultados obtidos,

Tabela 2 - Médias ( \pm erro-padrão) de quadrados mínimos dos pesos ao nascimento (PN), à desmama (P205), aos 12 (P365) e aos 18 (P550) meses de idade de bovinos da raça Nelore, de acordo com microrregião e sexo ${ }^{1}$

Table 2 - Least squares means ( \pm standard error) for body weights at birth (BW), weaning (W205), 12 (W365) and 18 (W550) months of age of Nellore cattle, by region and sex ${ }^{1}$

\begin{tabular}{lcccc}
\hline & PN $(\mathrm{kg})$ & P205 $(\mathrm{kg})$ & P365 $(\mathrm{kg})$ & W365 \\
Microrregião & $B W$ & W205 & $\begin{array}{c}\text { P550 }(\mathrm{kg}) \\
\text { W550 }\end{array}$ \\
\cline { 2 - 5 } Region & \multicolumn{4}{c}{ Machos } \\
Alto Taquari & $30,4 \pm 0,1^{\mathrm{c}}$ & $157,4 \pm 0,8^{\mathrm{c}}$ & $211,5 \pm 1,4^{\mathrm{c}}$ & $273,7 \pm 3,2^{\mathrm{b}}$ \\
Campo Grande & $31,0 \pm 0,1^{\mathrm{b}}$ & $161,7 \pm 0,6^{\mathrm{b}}$ & $225,1 \pm 1,2^{\mathrm{b}}$ & $301,8 \pm 3,0^{\mathrm{a}}$ \\
Pantanal & $31,3 \pm 0,1^{\mathrm{a}}$ & $164,5 \pm 0,5^{\mathrm{a}}$ & $231,8 \pm 1,0^{\mathrm{a}}$ & $298,6 \pm 3,0^{\mathrm{a}}$ \\
Média geral & $30,6 \pm 0,1^{\mathrm{A}}$ & $161,0 \pm 0,6^{\mathrm{A}}$ & $222,4 \pm 0,9^{\mathrm{A}}$ & $287,6 \pm 2,3^{\mathrm{A}}$ \\
General average & & & \\
\hline
\end{tabular}

\begin{tabular}{lllll}
\hline \multicolumn{4}{c}{ Fêmeas } \\
Females \\
\hline Alto Taquari & $28,5 \pm 0,1^{\mathrm{c}}$ & $143,4 \pm 0,9^{\mathrm{c}}$ & $186,5 \pm 1,3^{\mathrm{c}}$ & $236,3 \pm 1,8^{\mathrm{b}}$ \\
Campo Grande & $29,1 \pm 0,1^{\mathrm{b}}$ & $148,6 \pm 0,7^{\mathrm{b}}$ & $200,1 \pm 1,1^{\mathrm{b}}$ & $256,8 \pm 1,5^{\mathrm{a}}$ \\
Pantanal & $29,4 \pm 0,1^{\mathrm{a}}$ & $150,9 \pm 0,6^{\mathrm{a}}$ & $203,4 \pm 1,0^{\mathrm{a}}$ & $255,5 \pm 1,4^{\mathrm{a}}$ \\
Média geral & $29,2 \pm 0,1^{\mathrm{B}}$ & $148,0 \pm 0,6^{\mathrm{B}}$ & $197,7 \pm 0,9^{\mathrm{B}}$ & $250,5 \pm 2,2^{\mathrm{B}}$ \\
General average & & & &
\end{tabular}

${ }^{1}$ Letras minúsculas diferentes nas mesmas colunas representam diferenças significativas entre regiões $(P<0,05)$ e letras maiúsculas diferentes representam diferenças significativas entre os sexos $(P<0,05)$, pelo teste de Tukey.

${ }^{1}$ Different small letters in the same columns show significant difference between regions $(P<.05)$ and different capital letters in the same columns show significant difference between sexes $(P<.05)$, by Tukey test. 
em rebanhos da raça Nelore, por outros pesquisadores. Souza et al. (1997) obtiveram diferentes estimativas de herdabilidade para peso à desmama em função das regiões consideradas; os valores variaram de 0,22 (Alto Taquari-Bolsão - MS) a 0,38 (Araraquara - SP).

Silva (1990), estudando animais criados em várias regiões do Brasil, entre elas o Mato Grosso do Sul, estimou herdabilidade de 0,35 para P205 e 0,42 para P365. Eler et al. (1995) estimaram herdabilidade de 0,29 para PN, 0,14 para P205 e 0,17 para P365, enquanto Ribeiro et al. (2001) estimaram 0,16 para P205, 0,40 para P365 e 0,76 para P550, em rebanhos na Paraíba.

A variação e os valores relatados no presente trabalho, para a herdabilidade dos pesos estudados, podem ser considerados coerentes, pois estão dentro da faixa de variação apresentada na literatura.

São várias as razões por que os componentes de (co)variância e as estimativas de herdabilidade variam de uma região para outra. Segundo Falconer \& Mackay (1996), a herdabilidade é uma propriedade da população, do ambiente a que o animalé submetido, enquanto a variância ambiental é dependente das condições de cultura e manejo - maior variação ambiental reduz a herdabilidade; mais uniformidade provoca aumento da herdabilidade.

Os menores valores para os componentes de variância ambiental estimados na microrregião de Alto Taquari sugerem que as condições dentro desta microrregião são mais homogêneas que nas demais, e, apesar de mais estressante aos animais, em termos de recursos naturais, principalmente em relação à microrregião de Campo Grande, mostrou ser mais adequada à expressão das diferenças genéticas resultando em aumento da variância genética aditiva.

As diferenças encontradas nos componentes de (co)variância corroboram os resultados obtidos por DeNise et al. (1988), que, trabalhando com bovinos da raça Hereford, em diferentes ambientes (rico e pobre), justificaram as diferenças nas estimativas de herdabilidade para pesos pós-desmame à ação de conjuntos de genes diferentes sobre esta característica.

Diante da premissa de que, em ambientes distintos, qualquer uma das características estudadas (PN, P205, P365 ou P550) pode ter sido influenciada por conjuntos de genes diferentes, e que estes genes podem se expressar com intensidades diferentes, de acordo com o grau de semelhança ou diferença dentro ou entre ambientes, observou-se interação genótipo $\mathrm{x}$ ambiente.
As correlações genéticas aditivas e ambientais do peso à desmama com as demais características, obtidas nos arquivos de cada microrregião e na análise realizada no arquivo completo encontram-se na Tabela 4.

Tabela 3 - Herdabilidades e variâncias genéticas aditivas e variâncias ambientais para os pesos ao nascimento (PN), à desmama (P205), aos 12 (P365) e aos 18 (P550) meses de idade de bovinos Nelore nas microrregiões homogêneas estudadas

Table 3 - Heritabilities and aditive genetic and environmental variances for body weights at birth $(B W)$, weaning (W205), 12 (W365) and 18 (W550) months of age of Nellore cattle in each studied region

\begin{tabular}{|c|c|c|c|}
\hline & $h^{2}$ & $\sigma_{a}^{2}$ & $\sigma_{e}^{2}$ \\
\hline $\begin{array}{c}\text { Característica } \\
\text { Trait }\end{array}$ & \multicolumn{3}{|c|}{ Alto Taquari } \\
\hline $\mathrm{PN}$ & \multirow[t]{2}{*}{0,66} & \multirow[t]{2}{*}{2,06} & \multirow[t]{2}{*}{1,06} \\
\hline$B W$ & & & \\
\hline P205 & \multirow[t]{2}{*}{0,59} & \multirow[t]{2}{*}{226,55} & \multirow[t]{2}{*}{158,63} \\
\hline W205 & & & \\
\hline P365 & \multirow[t]{2}{*}{0,49} & \multirow[t]{2}{*}{302,59} & \multirow[t]{2}{*}{318,23} \\
\hline W365 & & & \\
\hline P550 & \multirow[t]{2}{*}{0,45} & \multirow[t]{2}{*}{410,86} & \multirow[t]{2}{*}{502,71} \\
\hline \multirow[t]{2}{*}{ W550 } & & & \\
\hline & \multicolumn{3}{|c|}{ Campo Grande } \\
\hline $\mathrm{PN}$ & \multirow[t]{2}{*}{0,16} & \multirow[t]{2}{*}{1,15} & \multirow[t]{2}{*}{5,99} \\
\hline$B W$ & & & \\
\hline P205 & \multirow[t]{2}{*}{0,36} & \multirow[t]{2}{*}{160,82} & \multirow[t]{2}{*}{283,51} \\
\hline W205 & & & \\
\hline P365 & \multirow[t]{2}{*}{0,38} & \multirow[t]{2}{*}{260,56} & \multirow[t]{2}{*}{427,09} \\
\hline W365 & & & \\
\hline P550 & \multirow[t]{2}{*}{0,34} & \multirow[t]{2}{*}{313,82} & \multirow[t]{2}{*}{607,91} \\
\hline W550 & & & \\
\hline & \multicolumn{3}{|c|}{ Pantanal } \\
\hline PN & 0,21 & 1,14 & 4,22 \\
\hline$B W$ & & & \\
\hline P205 & 0,37 & 163,13 & 273,39 \\
\hline$W 205$ & & & \\
\hline P365 & 0,35 & 249,75 & 463,36 \\
\hline W365 & & & \\
\hline P550 & 0,30 & 256,32 & 610,05 \\
\hline W550 & & & \\
\hline & & ivo com & \\
\hline & & ull data se & \\
\hline $\mathrm{PN}$ & 0,22 & 1,20 & 4,37 \\
\hline$B W$ & & & \\
\hline P205 & 0,43 & 188,56 & 246,47 \\
\hline$W 205$ & & & \\
\hline P365 & 0,40 & 274,73 & 417,07 \\
\hline W365 & & & \\
\hline P550 & 0,35 & 318,66 & 588,03 \\
\hline W550 & & & \\
\hline
\end{tabular}

${ }_{1}^{1}$ Arquivo com os dados das três microrregiões.

${ }^{1}$ Data set with records from the three regions.

R. Bras. Zootec., v.33, n.6, p.1445-1455, 2004 
As correlações genéticas aditivas entre P205 e PN foram menores que as correlações de P205 com P365 e P550, em todas as microrregiões (Tabela 4). Ressalta-se que a seleção baseada no maior peso à desmama acarretaria menores aumentos no peso ao nascimento, em relação aos acréscimos provocados nos P365 e P550. Apesar disso, deve-se tomar atentar para as modificações do PN, pois o aumento deste pode provocar maior incidência de partos complicados, prejudicando o desempenho reprodutivo das vacas.

Os valores obtidos para as correlações de peso à desmama com peso ao nascimento foram menores que o registrado $(0,61)$ por Melis et al. (2001). As correlações de peso à desmama com pesos aos $12 \mathrm{e}$ aos 18 meses de idade estão na faixa de variação constatada por vários pesquisadores, como Silva (1990), Ferraz Filho (1996), Silveira et al. (2000) e Souza et al. (2001), cujos valores são de 0,62 a 0,94, para P205 com P365, e de 0,61 a 0,86, para P205 com P550.

Tabela 4 - Correlações genéticas aditivas $\left(r_{a}\right)$ e ambientais $\left(r_{e}\right)$ do peso à desmama (P205) com os pesos ao nascimento (PN), aos 12 (P365) e aos 18 (P550) meses de idade de bovinos da raça Nelore nas microrregiões homogêneas estudadas

Table 4 - Aditive genetic $\left(r_{a}\right)$ and environmental $\left(r_{e}\right)$ correlations between body weights at weaning (W205) and body weights at birth (BW), 12 (W365) and 18 (W550) months of age of Nellore cattle in each studied region

\begin{tabular}{|c|c|c|c|}
\hline \multirow{3}{*}{$\begin{array}{l}\text { Microrregião } \\
\text { Region }\end{array}$} & \multicolumn{3}{|c|}{$\mathrm{r}_{\mathrm{a}}$} \\
\hline & PN & P365 & P550 \\
\hline & $B W$ & W365 & W550 \\
\hline Alto Taquari & 0,19 & 0,96 & 0,94 \\
\hline Campo Grande & 0,52 & 0,93 & 0,79 \\
\hline Pantanal & 0,29 & 0,93 & 0,89 \\
\hline Arquivo completo ${ }^{1}$ & 0,31 & 0,94 & 0,87 \\
\hline \multicolumn{4}{|l|}{ Full data set ${ }^{1}$} \\
\hline & \multicolumn{3}{|c|}{$\mathrm{r}_{\mathrm{e}}$} \\
\hline Microrregião & $\mathrm{PN}$ & P365 & P550 \\
\hline Region & $B W$ & W365 & W550 \\
\hline Alto Taquari & 0,14 & 0,37 & 0,29 \\
\hline Campo Grande & 0,10 & 0,50 & 0,45 \\
\hline Pantanal & 0,10 & 0,32 & 0,30 \\
\hline Arquivo completo ${ }^{1}$ & 0,11 & 0,38 & 0,36 \\
\hline Full data set ${ }^{1}$ & & & \\
\hline
\end{tabular}

${ }^{1}$ Arquivo com os dados das três microrregiões.

${ }^{1}$ Data set with records from the three regions.
As altas correlações de P205 com P365 e P550 indicam que grande parte dos genes de ação aditiva que atuam sobre o peso à desmama também atua sobre os pesos aos 12 e aos 18 meses de idade, na mesma direção, e sugerem que a seleção para maior peso à desmama, além de mais rápida e menos onerosa que para P365 e P550 (pois é medida no animal mais jovem), pode levar a ganhos favoráveis no peso aos 12 e aos 18 meses de idade, sendo, portanto, um bom critério de seleção.

A correlação genética entre PN e P205, obtida na análise dos dados da região de Campo Grande, foi a maior, enquanto entre P205 e P550, na mesma região, foi a menor (Tabela 4) entre as três regiões estudadas, contrariando os relatos de DeNise et al. (1988), que observaram que a correlação genética entre o peso ao nascimento e à desmama foi maior no ambiente com piores condições nutricionais. Uma das conseqüências das diferenças entre as correlações genéticas entre as regiões é que a resposta correlacionada, quando a seleção for baseada no maior P205, poderá ser maior para o PN e menor para o P550 na região de Campo Grande, em relação às demais.

As correlações ambientais estimadas entre o peso à desmama e o peso ao nascimento foram baixas (em média de 0,11). Quando a estação de nascimento ocorre no início da estação das águas, os bezerros nascem mais leves e, conseqüentemente, são desmamados após bom tempo em pastagens com maior disponibilidade de forragem, com boas condições ambientais para se desenvolverem, obtendo, portanto, crescimento compensatório. Quando a estação de nascimento ocorre no final da estação chuvosa, os bezerros nascem mais pesados, porém, como serão desmamados após o período de baixo desenvolvimento das pastagens e piores condições que na situação anterior, têm seu desenvolvimento comprometido pela qualidade e quantidade da forragem disponível.

As correlações ambientais estimadas entre peso à desmama e pesos aos 12 e 18 meses de idade foram, em média, de 0,39 e 0,35 . As estimativas de correlação ambiental de P205 com P365 e P550 foram semelhantes às descritas por Souza et al. (2001), 0,44 e 0,39 , respectivamente, e inferiores às de Ferraz Filho (1996), de 0,61 e 0,51, na mesma ordem.

A variação sazonal da disponibilidade de forragem pode ser um dos fatores que contribui para essas correlações de média magnitude. Porém, correlações 
positivas indicam que os efeitos de meio favoráveis ao peso à desmama também contribuem para maiores pesos aos 12 e aos 18 meses de idade.

Nas Tabelas 5, 6, 7 e 8, são apresentadas as correlações de Pearson entre os valores genéticos preditos e as de Spearman entre a classificação dos touros obtidas com base no valor genético predito para os pesos ao nascimento, à desmama, aos $12 \mathrm{e}$ aos 18 meses de idade, respectivamente, tanto entre os valores obtidos nas análises dos arquivos das microrregiões como destes com o arquivo completo.

As correlações entre os valores genéticos dos reprodutores presentes no arquivo de cada microrregião e no arquivo completo foram altas, uma indicação de que, na avaliação genética com base no arquivo completo - como nas avaliações de gado de corte para o rebanho nacional -, há tendência de minimizar a importância da interação genótipo $\mathrm{x}$ ambiente, visto que a menor variância genética manifestada em determinadas microrregiões tende a ser compensada por valores elevados de outras, nas microrregiões Alto Taquari e Campo Grande, relativamente contrastantes em termos de qualidade de ambiente para a produção animal (Tabela 3).
As correlações entre os valores genéticos (Pearson) e entre a classificação dos touros (Spearman), com base nos valores genéticos para PN nas microrregiões entre si, são baixas, evidenciando diferenças no peso ao nascimento da progênie dos animais em função das regiões em que são criadas, o que caracteriza manifestação da interação genótipo x ambiente. Apesar de se considerar essa característica influenciada principalmente pela mãe, observou-se que a diferença de ambiente a afetou, mesmo que indiretamente, e, como relatado por Euclides Filho (1984), para o peso ao nascimento e à desmama, parte dessa interação pode ser atribuída à interação genótipo da mãe $\mathrm{x}$ ambiente desta.

Para o peso à desmama, as correlações de Pearson e de Spearman entre os valores genéticos dos touros, calculadas com as informações de suas progênies em duas microrregiões, são baixas (Tabela 6), evidenciando diferenças na expressão desta característica em função das regiões onde os filhos foram criados. Para os pesos aos 12 e aos 18 meses de idade (Tabelas 7 e 8), os resultados foram semelhantes aos do peso à desmama, ao serem analisados os valores das correlações entre os valores genéticos dos touros com as informações de suas

Tabela 5 - Correlações de Pearson entre os valores genéticos preditos (acima da diagonal) e correlações de Spearman entre a classificação dos touros com base no valor genético predito (abaixo da diagonal) para o peso ao nascimento nas microrregiões estudadas ${ }^{1}$

Table 5 - Pearson correlations between predict breeding values (above the diagonal) and Spearman rank correlations between the predict breeding value (below the diagonal) for birth weigth in studied regions

\begin{tabular}{ccccc}
\hline & \multicolumn{3}{c}{$\begin{array}{c}\text { Microrregião } \\
\text { Region }\end{array}$} \\
\cline { 2 - 4 } $\begin{array}{c}\text { Microrregião } \\
\text { Region }\end{array}$ & Alto Taquari & Campo Grande & Pantanal & $\begin{array}{c}\text { Arquivo completo }{ }^{2} \\
\text { Full data set }^{2}\end{array}$ \\
\hline Alto Taquari & & $-0,040^{\mathrm{ns}}$ & $0,106^{\mathrm{ns}}$ & $0,661^{*}$ \\
Campo Grande & $-0,073^{\mathrm{ns}}$ & $(71)$ & $(57)$ & $(174)$ \\
Pantanal & $(71)$ & & $0,272^{*}$ & $0,846^{*}$ \\
& $0,102^{\mathrm{ns}}$ & $0,240^{*}$ & $(112)$ & $(445)$ \\
Arquivo completo & $(57)$ & $(112)$ & & $0,905^{*}$ \\
Full data set $^{2}$ & $0,617^{*}$ & $0,833^{*}$ & $0,897^{*}$ & $(364)$ \\
\hline
\end{tabular}

1 Os números entre parênteses representam o número de touros envolvidos nas análises de correlação.

2 Arquivo com os dados das três microrregiões.

* Correlação estatisticamente diferente de $0(P<0,05)$.

ns Correlação não-significativa $(P>0,05)$.

1 The numbers whitin parenteses is the number of bulls in the correlation analyses.

2 Data set with records from the three regions.

* Correlations statisticaly different from $0(P<.05)$.

ns Not significant correlation $(P>.05)$. 
Tabela 6 - Correlações de Pearson entre os valores genéticos preditos (acima da diagonal) e de Spearman entre a classificação dos touros com base no valor genético predito (abaixo da diagonal) para o peso à desmama nas microrregiões estudadas ${ }^{1}$

Table 6 - Pearson correlations between predict breeding values (above the diagonal) and Spearman rank correlations between the predict breeding value (below the diagonal) for wearning weigth in studied regions ${ }^{1}$

\begin{tabular}{ccccc}
\hline & \multicolumn{3}{c}{$\begin{array}{c}\text { Microrregião } \\
\text { Region }\end{array}$} \\
\cline { 2 - 4 } $\begin{array}{c}\text { Microrregião } \\
\text { Region }\end{array}$ & Alto Taquari & Campo Grande & Pantanal & $\begin{array}{c}\text { Arquivo completo }^{2} \\
\text { Full data set }^{2}\end{array}$ \\
\hline Alto Taquari & & $0,365^{*}$ & $0,440^{*}$ & $0,860^{*}$ \\
Campo Grande & $0,471^{*}$ & $(71)$ & $(57)$ & $(174)$ \\
Pantanal & $(71)$ & & $0,330^{*}$ & $0,886^{*}$ \\
Arquivo completo & $0,418^{*}$ & $0,306^{*}$ & $(112)$ & $(445)$ \\
Full data set & $(57)$ & $(112)$ & & $0,899^{*}$ \\
\hline & $0,871^{2}$ & $0,892^{*}$ & $0,891^{*}$ & $(364)$ \\
\hline
\end{tabular}

1 Os números entre parênteses representam o número de touros envolvidos nas análises de correlação.

2 Arquivo com os dados das três microrregiões.

* Correlação estatisticamente diferente de $0 \quad(P<0,05)$.

ns Correlação não-significativa $(P>0,05)$.

1 The numbers whitin parenteses is the number of bulls in the correlation analyses.

2 Data set with records from the three regions.

* Correlations statisticaly different from $0(P<.05)$

ns Not significant correlation ( $P>$.05).

Tabela 7 - Correlações de Pearson entre os valores genéticos preditos (acima da diagonal) e de Spearman entre a classificação dos touros com base no valor genético predito (abaixo da diagonal) para o peso aos 12 meses de idade nas microrregiões estudadas ${ }^{1}$

Table 7 - Pearson correlations between predict breeding values (above the diagonal) and Spearman rank correlations between the predict breeding value (below the diagonal) for the weight at 12 months of age in studied regions

\begin{tabular}{ccccc}
\hline & \multicolumn{3}{c}{$\begin{array}{c}\text { Microrregião } \\
\text { Region }\end{array}$} \\
\cline { 2 - 4 } $\begin{array}{c}\text { Microrregião } \\
\text { Region }\end{array}$ & Alto Taquari & Campo Grande & Pantanal & $\begin{array}{c}\text { Arquivo completo }{ }^{2} \\
\text { Full data set }^{2}\end{array}$ \\
\hline Alto Taquari & & $0,396^{*}$ & $0,461^{*}$ & $0,852^{*}$ \\
Campo Grande & 0,453 & $(71)$ & $(57)$ & $(174)$ \\
Pantanal & $(71)$ & & 0,292 & $0,886^{*}$ \\
Arquivo completo & $0,426^{*}$ & $0,273^{*}$ & $(112)$ & $(445)$ \\
Full data set & $(57)$ & $(112)$ & & $(364)$ \\
\hline
\end{tabular}

1 Os números entre parênteses representam o número de touros envolvidos nas análises de correlação.

2 Arquivo com os dados das três microrregiões.

* Correlação estatisticamente diferente de $0 \quad(P<0,05)$.

ns Correlação não-significativa $(P>0,05)$.

1 The numbers whitin parenteses is the number of bulls in the correlation analyses.

2 Data set with records from the three regions.

* Correlations statisticaly different from $0(P<.05)$.

ns Not significant correlation $(P>05)$. 
progênies em duas microrregiões, como também entre uma microrregião e o arquivo completo, o que se deve, em parte, às altas correlações genéticas e moderadas correlações ambientais (Tabela 4) entre estes pesos (Silva, 1990).

As correlações entre os valores genéticos dos touros para a mesma característica em duas microrregiões foram em torno de 0,32 , valor que pode ser indicador de interação genótipo $\mathrm{x}$ ambiente nas características avaliadas e dar suporte à hipótese de que os touros não apresentam o mesmo desempenho em todas as microrregiões, tornando importante a inclusão da região de nascimento do animal quando da realização de avaliação genética de animais de reprodução.

As correlações entre os valores genéticos e entre a classificação dos animais assumem grande importância quando se considera que, em programas de seleção, apenas os indivíduos com os melhores valores genéticos são escolhidos para reprodução e, sendo os valores de correlação baixos, um touro escolhido com base nas informações dos filhos criados em determinada região poderia não ser escolhido se avaliado pelas informações de seus filhos criados em outras regiões.
Os resultados deste trabalho estão de acordo com os de Butts et al. (1971), que, ao estudarem duas linhagens de bovinos Hereford, mantidas em seu local de origem e em novo ambiente, verificaram que a interação local de origem $\mathrm{x}$ local de criação foi significativa $(\mathrm{P}<0,01)$ para peso ao nascimento, peso à desmama e ganho em peso do nascimento à desmama de bezerros machos e fêmeas. Verificaram ainda que as linhagens locais foram sempre superiores às linhagens introduzidas.

Resultados contrários foram obtidos por Mattos et al. (2000), ao avaliarem a correlação genética entre o peso à desmama de bovinos Hereford, considerada característica distinta em função da região dos Estados Unidos, onde os animais foram criados - estimaram valores próximos a 0,85 , não encontrando, interação genótipo $\mathrm{x}$ ambiente para esta característica.

A existência de interação genótipo $\mathrm{x}$ ambiente implica na alteração da classificação dos animais e pode levar à escolha de touros inadequados para certas regiões e prejudicar o progresso genético dos rebanhos.

Tabela 8 - Correlações de Pearson entre os valores genéticos preditos (acima da diagonal) e de Spearman entre a classificação dos touros com base no valor genético predito (abaixo da diagonal) para o peso aos 18 meses de idade nas microrregiões estudadas ${ }^{1}$

Table 8 - Pearson correlations between predict breeding values (above the diagonal) and Spearman's rank correlations between the predict breeding value (below the diagonal) for the weight at 18 months of age in studied regions

\begin{tabular}{ccccc}
\hline & \multicolumn{3}{c}{$\begin{array}{c}\text { Microrregião } \\
\text { Region }\end{array}$} & \\
\cline { 2 - 4 } $\begin{array}{c}\text { Microrregião } \\
\text { Region }\end{array}$ & Alto Taquari & Campo Grande & Pantanal & $\begin{array}{c}\text { Arquivo completo } \\
\text { Full data set }^{2}\end{array}$ \\
\hline Alto Taquari & & $0,398^{*}$ & $0,471^{*}$ & $0,867^{*}$ \\
& & $(71)$ & $(57)$ & $(174)$ \\
Campo Grande & $0,415^{*}$ & & $0,306^{*}$ & $0,876^{*}$ \\
& $(71)$ & & $(112)$ & $(445)$ \\
Pantanal & $0,457^{*}$ & $0,330^{*}$ & & $0,876^{*}$ \\
& $(57)$ & $(112)$ & $0,883^{*}$ & $(364)$ \\
Arquivo completo & $0,869^{*}$ & $0,875^{*}$ & $(364)$ & \\
Complete data set $^{2}$ & $(174)$ & $(445)$ & & \\
\hline
\end{tabular}

1 Os números entre parênteses representam o número de touros envolvidos nas análises de correlação.

2 Arquivo com os dados das três microrregiões.

* Correlação estatisticamente diferente de $0 \quad(P<0,05)$.

ns Correlação não-significativa $(P>0,05)$.

1 The numbers whitin parenteses is the number of bulls in the correlation analyses.

2 Data set with records from the three regions.

* Correlations statisticaly different from $0(P<.05)$.

ns Not significant correlation $(P>.05)$. 


\section{Conclusões}

Existem evidências de interação genótipo $\mathrm{x}$ ambiente para os pesos indicadores de desenvolvimento ponderal de bovinos Nelore, havendo possibilidade de os animais selecionados como de mérito genético superior para uma região não o serem para outras.

A escolha de reprodutores com base nos valores genéticos obtidos em análise geral, cujo banco de dados tem informações de regiões distintas e em que é considerado o efeito de região de criação das progênies nas análises, pode ser mais eficiente para o melhoramento de rebanhos de regiões específicas, se estas forem correlacionadas positivamente com os reprodutores escolhidos. Portanto, deve-se ter cuidado especial na utilização de animais selecionados em regiões diferentes daquelas em que as progênies serão criadas.

Os altos valores de correlações entre os pesos em diferentes idades indicam ser o peso à desmama um critério de seleção eficiente também para ganho nos demais.

\section{Literatura Citada}

ARRUDA, Z.J.; SUGAI, Y. Regionalização da pecuária bovina no Brasil. Campo Grande: EMBRAPA-CNPGC, 1994. $144 \mathrm{p}$.

BOLDMAN, K.G.; KRIESE, L.A.; Van VLECK, L.D. A set of programs to obtain estimates of variance and covariances [DRAFT]. Lincoln: Department of Agriculture/Agricultural Research Service, 1995. 120p.

BUTTS, W.T.; KOGER, M.; PAHNISH, O.F. et al. Performance of two lines of Hereford cattle in two environments. Journal of Animal Science, v.33, n.5, p.923-932, 1971.

CAMPÊLO, J.E.G.; LOPES, P.S.; TORRES, R.A. et al. Efeitos maternos na avaliação genética de reprodutores da raça Tabapuã. In: REUNIÃO ANUAL DA SOCIEDADE BRASILEIRA DE ZOOTECNIA, 38., 2001, Piracicaba. Anais... Piracicaba: Sociedade Brasileira de Zootecnia, 2001. p.517-518.

CARDELLINO, R.A.; CAMPOS, L.T.; CARDOSO, F.F. Interação genótipo-ambiente nas raças Hereford e Aberdeen Angus: DEPs nos EUA e no Brasil. In: REUNIÃO ANUAL DA SOCIEDADE BRASILEIRA DE ZOOTECNIA, 34., 1997, Juiz de Fora. Anais... Juiz de Fora: Sociedade Brasileira de Zootecnia, 1997. p.190-192.

DeNISE, R.S.K.; TORABI, M.; RAY, D.E. et al. Genetic parameter estimates for post weaning traits of beef cattle in a stressful environment. Journal of Animal Science, v.66, n.8, p.1899-1906, 1988.

ELER, J.P.; Van VLECK, L.D.; FERRAZ, J.B.S. et al. Estimation of variances due to direct and maternal effects for growth traits of nelore cattle. Journal of Animal Science, v.73, n.11, p.3253-3258, 1995.

\footnotetext{
R. Bras. Zootec., v.33, n.6, p.1445-1455, 2004
}

EUCLIDES FILHO, K. Effects of genotype by environment interactions on beef cattle performance at two locations. Gainesville: University of Florida, 1984. 96p. Tese (Doutorado em Melhoramento Animal) - University of Florida, 1984.

FALCONER, D.S.; MACKAY, T.F.C. Introduction to quantitative genetics. 4.ed. Edinburgh: Longman, 1996. $464 \mathrm{p}$.

FERRAZ FILHO, P.B. Análise e tendência genética de pesos em bovinos da raça nelore mocha no Brasil. Jaboticabal: Universidade Estadual Paulista, 1996. 163p. Dissertação (Mestrado em Genética e Melhoramento Animal) Universidade Estadual Paulista, 1996.

FRIES, L.A.; ROSO, V.M. Conectabilidade em avaliações genéticas de gado de corte: uma proposta heurística. In: REUNIÃO ANUAL DA SOCIEDADE BRASILEIRA DE ZOOTECNIA, 34., 1997, Juiz de Fora. Anais... Juiz de Fora: Sociedade Brasileira de Zootecnia, 1997. p.159-161.

INSTITUTO BRASILEIRO DE GEOGRAFIA E ESTATÍSTICA - IBGE. Divisão do Brasil em microrregiões homogêneas 1968. Rio de Janeiro: IBGE, 1970. 567p.

MACHADO, P.F.A.; AQUINO, L.H.; GONÇALVES, T.M. et al. Influência de fatores de meio sobre características produtivas de animais da raça nelore. In: REUNIÃO ANUAL DA SOCIEDADE BRASILEIRA DE ZOOTECNIA, 34., 1997, Juiz de Fora. Anais... Juiz de Fora: Sociedade Brasileira de Zootecnia, 1997. p.211-213.

MATTOS, D.; BERTRAND, J.K.; MISZTAL, I. Investigation of genotype $\mathrm{x}$ environment interactions for weaning weight for Herefords in three countries. Journal of Animal Science, v.78, n.8, p.2121-2126, 2000.

MASCIOLI, A.S. Interação genótipo $\mathbf{x}$ ambiente sobre 0 desempenho de animais canchim e cruzados canchim $\mathbf{x}$ nelore. Jaboticabal: Universidade Estadual Paulista, 2000. 99p. Tese (Doutorado em Produção Animal) - Universidade Estadual Paulista, 2000.

MELIS, M.H.V.; SILVA, J.A.II.V.; ELER, J.P. et al. Relação genética entre peso ao nascimento e peso à desmama em bovinos da raça nelore. In: REUNIÃO ANUAL DA SOCIEDADE BRASILEIRA DE ZOOTECNIA, 38., 2001, Piracicaba. Anais... Piracicaba: Sociedade Brasileira de Zootecnia, 2001. p.515-517.

NOBRE, P.R.C.; ROSA, A.N.; EUCLIDES FILHO, K. Interação genótipo x ambiente em gado nelore. Revista da Sociedade Brasileira de Zootecnia, v.16, n.4, p.352-363, 1987.

RIBEIRO, M.N.; PIMENTA FILHO, E.C.; MARTINS, G.A. et al. Herdabilidade para efeitos direto e materno de características de crescimento de bovinos nelore no estado da Paraíba. Revista Brasileira de Zootecnia, v.30, n.4, p.1224-1227, 2001.

SAKAGUTI, E.S.; SILVA, M.A.; MARTINS, E.N. et al. Efeito da idade da mãe e do sexo do animal sobre o peso corporal de bovinos Tabapuã em diferentes idades. In: REUNIÃO ANUAL DA SOCIEDADE BRASILEIRA DE ZOOTECNIA, 38., 2001, Piracicaba. Anais... Piracicaba: Sociedade Brasileira de Zootecnia, 2001. p.552-553.

STATISTICAL ANALYSES SYSTEMS - SAS. User's guide. Version 8. 2.ed. Cary: 2001.

SILVA, L.O.C. Tendência genética e interação genótipo $\mathbf{x}$ ambiente em rebanhos Nelore, criados a pasto no Brasil Central. Viçosa, MG: Universidade Federal de Viçosa, 1990. 113p. Tese (Doutorado em Genética e Melhoramento) Universidade Federal de Viçosa, 1990. 
SILVEIRA, J.C.; SOUZA, A.P.; MAcMANUS, C. et al. Parâmetros genéticos e ambientais de características produtivas em animais da raça nelore no Mato Grosso do Sul. In: REUNIÃO ANUAL DA SOCIEDADE BRASILEIRA DE ZOOTECNIA, 37., 2000, Viçosa. Anais... São Paulo: SBZ/Gmosis, [2000]. CD-ROOM. Melhoramento Animal. SOUZA, J.C.; EUCLIDES FILHO, K.; SILVA, L.O.C. et al. Estimativa de parâmetros genéticos para o peso ao desmame de animais da raça nelore no Brasil. In: REUNIÃO ANUAL DA SOCIEDADE BRASILEIRA DE ZOOTECNIA, 34., 1997, Juiz de Fora. Anais... Juiz de Fora: Sociedade Brasileira de Zootecnia, 1997. p.251-253.
SOUZA, J.C.; SILVA, L.O.C.; MALHADO, C.H.M. et al. Estudo das correlações genéticas, fenotípicas e de ambiente entre os pesos de várias idades em bovinos da raça guzerá no estado de São Paulo. In: REUNIÃO ANUAL DA SOCIEDADE BRASILEIRA DE ZOOTECNIA, 38., 2001, Piracicaba. Anais... Piracicaba: Sociedade Brasileira de Zootecnia, 2001. p.609-611.

Recebido em: 31/09/02

Aceito em: 05/12/03 